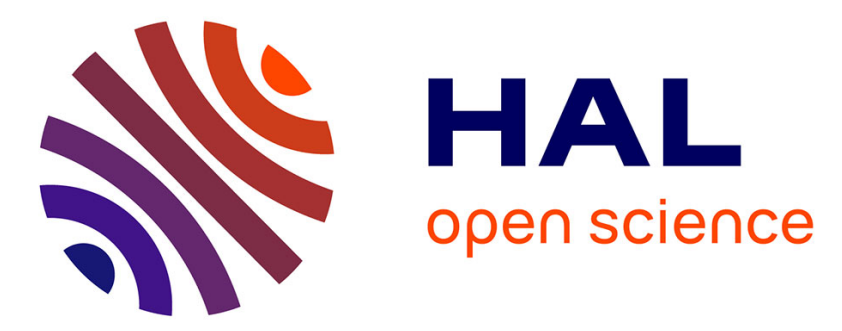

\title{
3D Collaborative Interaction for Aerospace Industry
}

Damien Clergeaud, François Guillaume, Pascal Guitton

\section{To cite this version:}

Damien Clergeaud, François Guillaume, Pascal Guitton. 3D Collaborative Interaction for Aerospace Industry. 3D CVE Workshop (IEEE VR), Mar 2016, Greenville, United States. pp.2. hal-01417208

\section{HAL Id: hal-01417208 \\ https://hal.inria.fr/hal-01417208}

Submitted on 15 Dec 2016

HAL is a multi-disciplinary open access archive for the deposit and dissemination of scientific research documents, whether they are published or not. The documents may come from teaching and research institutions in France or abroad, or from public or private research centers.
L'archive ouverte pluridisciplinaire HAL, est destinée au dépôt et à la diffusion de documents scientifiques de niveau recherche, publiés ou non, émanant des établissements d'enseignement et de recherche français ou étrangers, des laboratoires publics ou privés. 


\title{
3D Collaborative Interaction for Aerospace industry
}

\author{
Damien CLERGEAUD ${ }^{1}$ François GUILLAUME ${ }^{2}$ Pascal GUITTON ${ }^{3,1}$ \\ ${ }^{1}$ Inria \\ ${ }^{2}$ Airbus Group \\ ${ }^{3}$ Université de Bordeaux
}

\begin{abstract}
3D collaborative interaction raises issues like awareness of the Virtual Environment that have been well known for some time. They have been the subject of research activities that have led to some interesting results described in the literature. Unfortunately, most of these results have not yet been not implemented in the software systems daily used by industry and remains only theoretical concepts. That is why we recently started a project to transfer some of these results in the aerospace industry for the Airbus Group. Beyond this first transfer target, we also intend to measure the real gains (in real industrial conditions) for the users, and then for the company. This second goal is essential because in most publications, user testing is not satisfying (lack of real users, lack of real procedures, non significant number of subjects). In this paper, we describe the first step of this work in progress and more precisely, the basic interaction features we have developed. Currently, we are designing the first user tests.
\end{abstract}

\section{Presentation of the Overall Context}

Virtual reality has been entering the industrial world for a long time. It is now used routinely in design and manufacturing processes mainly in large companies. In this project, we consider a specific industrial context: aerospace with Airbus Group. Airbus Group have been using VR for more than ten years to design and develop their aerospace products. A second major step will be to perform more complex experiments simultaneously involving several remote sites. For instance, if a complex problem occurs during the final stages of assembling a launcher, it may be necessary to involve experts who were involved in the initial design and/or the initial assembly. Traditionally these meetings are held over the telephone or using videoconferencing. Airbus would like to replace them with collaborative VR working sessions between multiple remote sites.

It is well known that such sessions raise complex issues particularly for interaction between users. The first is the awareness of the Virtual Environment: when a user is immersed, it may be very difficult to fully perceive - and then, understand the VE. Of course, the more complex the VE is, the more difficult it is to understand. So, improving awareness is still a big challenge for collaborative interaction in VR and several aspects must be considered [8]:

- Components of the VE: it is not easy to fully perceive a dense environment like the inside of a launcher (figure 1). There are lots of technical components (pipes, harnesses equipement...) which may induce occlusions that prevent the user from seeing the whole VE at a single glance. Moreover, it is easy to get disoriented, especially, when complex operations which induce forced body movements are required. Therefore, it is necessary to provide users with efficient spatial referencing tools so that they know precisely where they are in the VE [10].

* Damien.Clergeaud@inria.fr,

Francois.Guillaume@airbus.com, Pascal.Guitton@inria.fr
- Other immersed Users: if multiple users are simultaneously immersed, it may be difficult for one user to perceive the location and/or the actions of the other users. When remote immersed users have to cooperate to perform a collaborative task, they have to know what the other operators are viewing in the VE. So displaying avatars or providing remote visualization is very useful $[1,7,4]$.

- Procedure: in order to perform complex tasks, users must check the progress of the overall procedure and mainly what other users are doing. Moreover immersed users have to communicate with others to synchronize their own actions with the actions of remote users $[3,5,6]$.

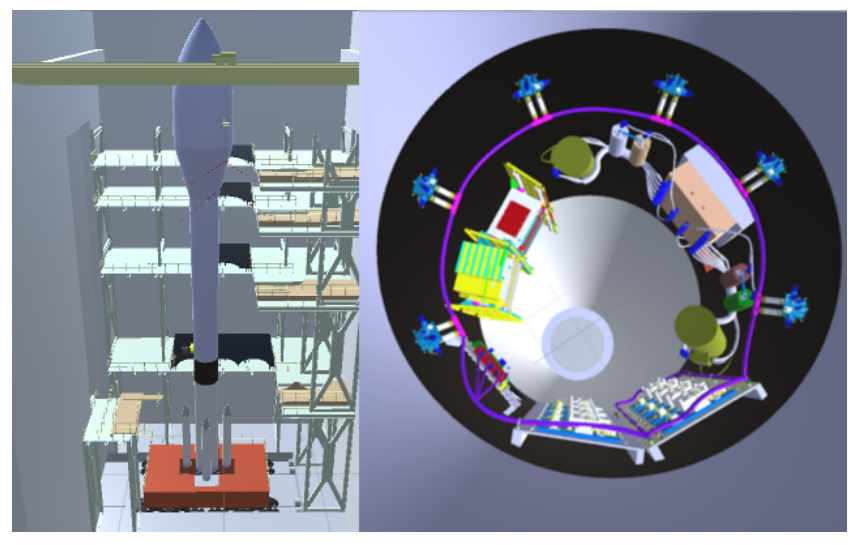

Figure 1: On the left, an outside view of the digital mock-up of a launcher and on the right, an inside top-down view.

Unfortunately, some solutions to these problems can be antagonistic. For instance, adding additional viewing windows to address the problem of remote visualization may decrease the feeling of presence and therefore awareness. Consequently, trying to perform efficient collaborative working sessions is much more complex than simply finding three separate solutions to these three issues. It is therefore necessary to establish balance between sometimes opposing constraints.

In order to provide efficient solutions to this global challenge, we first observed the current industrial procedures in VR experiments. Then we started to develop some basic collaborative interaction features based on previous work. These first features have already been tested and validated by Airbus experts. The second step is to integrate them into the operational software systems used by Airbus. The third step is to test these features in real conditions: real users and procedures, with a significant number of users.

\section{Description of the Current System}

We are designing a system which offers interaction tools that improve awareness for immersed users. The purpose of these tools 
is to adress issues that often occur during real VR collaborative sessions : Where are you ? What do you see? Which component are you talking about ? etc. In current sessions, we observed that these exchanges (questions, answers) are almost exclusiveley oral. They generate noise and interference and cause a lot of repetition between the users. The system we are developing is intended to reduce/eliminate these drawbacks by replacing most of the oral exchanges by VR interaction tools. It seems that it is easier to describe a position in the VE or to designate a $3 \mathrm{D}$ object by showing the information in the scene through an appropriate metaphor.

\subsection{Basic Designation Features}

In the VE, users are represented by a virtual head and a virtual hand. In order to ease the manipulation and to access a virtual menu, they can switch their virtual hand to a virtual ray.

To show a specific component, users can either use a virtual ray [6] or highlight it. In the first case, the designation is dynamic and doesn't modify the 3D scene. In the second case, the designation is more persistent and users may choose between several designation metaphors:

- Bounding volume: the component is surrounded by a transparent sphere.

- Spotlight: the component is highlighted by a spotlight and ambient light is lowered in order to obtain a more noticeable contrast.

- Flashing Texture: the texture of the component is visible intermittently.

- Outline shader: the component is surrounded by a color line. It remains visible if it is hidden by other objects.

\subsection{Remote Visualization}

In order to better perceive what other users are seeing, multiple views are often displayed in a splitscreen [2, 9]. This kind of display is very useful in classical $3 \mathrm{D}$ expriments but in a VR context, it can significantly reduce, or even break, the feelings of immersion and presence. For this reason, we enable the immersed user to define $3 \mathrm{D}$ camera(s) in the global scene and to display the view(s) in additional window(s) in the VE. A camera and a window are defined as $3 \mathrm{D}$ objects in the scene and can be manipulated by users like other objects. They can modify all the parameters of the camera.

These cameras can be placed before the session by a master operator. To understand their specific task, users have to check all these preset flows.

Based on the same principle (window and camera), immersed users can get the viewpoint of remote users to see what they are currently doing or what they are talking about.

\subsection{Component Trajectory}

In order to explain/understand a global process, it may be useful to show the trajectory of some components during the progress of the task. For instance, showing the movement of a tool from the workbench to its area of use, or the movement of a component that must be introduced/removed in/from the launcher.

This is the reason why we are developing a tool to define trajectories in the virtual environment. The trajectory can be defined during the working session by manually placing and orienting a sequence of points or by capturing a 3D movement using a tracking sensor. These two modes can be mixed; for instance, by first quickly defining a rough trajectory using some individual points and second, by refining parts that need more precision. A trajectory can be visualized by dynamically moving the component linked to it following the 3D path. The trajectory is a real 3D line (gathering not only the localization of each point but also its orientation) enabling movements of components « around» the trajectory. For instance, we can precisely describe the path of a tool so that it can pass through a small window which forces it to modify its orientation.

As with the cameras, a master user can define, before the session, the trajectories of some components during a task. The final user has to play each trajectory to understand the global task.

\section{Conclusion}

After having developed basic interaction features, we are now designing a test protocol in order to study these tools both quantitatively and qualitatively. We intend to measure some real industrial task executions (time, precision) and to ask users for feedback (comfort, acceptability...). Thanks to these tests, we want to analyze the real benefits taking into account the additional cognitive load. These tests aim to first measure the gains for the users and second try to analyze the contribution of these interaction features towards improving global awareness. More precisely, we intend to quantitatively and qualitatively refine the following figure showing how the interaction features contribute to the collaboration.

\begin{tabular}{l|ccc}
\multicolumn{1}{c}{ Components } & Other Users & Procedure \\
\hline $\begin{array}{l}\text { Designation } \\
\text { Metaphor }\end{array}$ & $\mathrm{x}$ & $\mathrm{x}$ & $\mathrm{x}$ \\
$\begin{array}{l}\text { Remote } \\
\text { Visualization }\end{array}$ & $\mathrm{x}$ & $\mathrm{x}$ & $\mathrm{x}$ \\
$\begin{array}{l}\text { Component } \\
\text { Trajectories }\end{array}$ & $\mathrm{x}$ & & $\mathrm{x}$
\end{tabular}

Figure 2: This table describes the awareness categories to which the interaction features contribute

In the future, we plan to design new and original interaction features for adding 3D annotations (text, images, sounds) and for helping complex component manipulation involving more than a single user.

\section{REFERENCES}

[1] Beck, S., Kunert, A., Kulik, A., \& Froehlich, B. (2013). Immersive group-to-group telepresence. IEEE Transactions on Visualization and Computer Graphics, 19(4), 616-25.

[2] Dodds, T. J., \& Ruddle, R. A. (2008). Using teleporting, awareness and multiple views to improve teamwork in collaborative virtual environments. $14^{\text {th }}$ Eurographics Symposium on Virtual Environments. 81-88

[3] Fleury, C., Chauffaut, A., Duval, T., Gouranton, V., \& Arnaldi, B. (2010). A Generic Model for Embedding Users'Physical Workspaces into Multi-Scale Collaborative Virtual Environments. ICAT 2010 (20 ${ }^{\text {th }}$ International Conference on Artificial Reality and Telexistence).

[4] Fraser, M., Benford, S., Hindmarsh, J., \& Heath, C. (1999). Supporting awareness and interaction through collaborative virtual interfaces. Proceedings of the 12th Annual ACM Symposium on User Interface Software and Technology - UIST '99, 1,27-36.

[5] Heldal, I., Schroeder, R., Steed, A., Axelsson, A.-S., Spante, M., \& Wideström, J. (2005). Immersiveness and symmetry in copresent scenarios. Virtual Reality, 2005, (March), 171-178. 
[6] Hrimech, H., Alem, L., \& Merienne, F. (2011). How 3D Interaction Metaphors Affect User Experience in Collaborative Virtual Environment. Advances in Human-Computer Interaction, 2011, 111.

[7] Leigh, J., Johnson, A. E., Vasilakis, C. A., \& DeFanti, T. A. (1996). Multi-perspective collaborative design in persistent networked virtual environments. Proceedings of the IEEE 1996 Virtual Reality Annual International Symposium, 253-260.

[8] Nguyen, T. T. H., \& Duval, T. (2014). A Survey of Communication and Awareness in Collaborative Virtual Environments. 2014 International Workshop on Collaborative Virtual Environments (3DCVE).

[9] Nguyen, T. T. H., Duval, T., Fleury, C. (2013). Guiding Techniques for Collaborative Exploration in Multi-Scale Shared Virtual Environments, International Conference on Computer Graphics Theory and Applications, 327-336.

[10] Stoakley, R., Conway, M. J., \& Pausch, R. (1995). Virtual Reality on a WIM: Interactive Worlds in Miniature. Proceedings of the ACM SIGCHI Conference on Human Factors in Computing Systems, 265272. 